\title{
A CONTRIBUTION TO RESEARCH OF THE INFLUENCE OF STEERING TRAPEZE ON BUS STEERED WHEELS SHIMMY
}

\author{
Dr Miroslav Demić* \\ University of Kragujevac, Faculty of Engineering Science, Kragujevac, Serbia \\ Dr Đorđe Diligenski \\ University of Belgrade, Vinča Institute of Nuclear Sciences, Belgrade, Serbia
}

Steered wheels shimmy is a harmful phenomenon in the steering system of the vehicle. It causes driver's fatigue and fatigue of the elements of steering system, increased tire wear etc. In practice, efforts are being made to reduce or eliminate the occurrence of this effect, and the buses are sometimes equipped with shock absorbers in the steering trapeze. In this paper an attempt is made to analyze the influence of shock absorber in the steering trapeze on the steered wheels shimmy of a bus. Analysis showed that shock absorbers significantly affect the reduction of steered wheels shimmy.

Key words: Bus, Shock absorber, Steered wheels shimmy

\section{INTRODUCTION}

Today there is a variety of systemic and design solutions in terms of meeting the basic functions of the steering system. In addition to the main task - to ensure the vehicle motion in the desired direction - the steering system has to meet a number of other requirements, some of the most important are the following [01, 03, 11-22]:

- acceptable steering accuracy and minimal lateral slip of steered wheels,

- spontaneous return of turned steered wheels into neutral position,

- low internal losses,

- acceptable level of handling the vehicle, primarily from the aspect of physical effort while controlling the steering wheel (low torque at the steering wheel with optimal turn of the steering wheel), also from the aspect of a sense of steering control (proportionality of the torque applied on the steering wheel and steered wheels resistance to turning),

- low level of system vibration,

- kinematic conformity with the vehicle suspension system,

- high reliability in the operation and steering the vehicle on the road in all conditions, and
- long life and easy maintenance.

In this paper, special attention will be paid to the vibration of steering system, in particular steering wheels shimmy. Actually, steered wheels shimmy refers to the steered wheels angular vibration about the king pin [03, 04-08, 11-22]. Steered wheels shimmy is a harmful phenomenon, because it leads to the fatigue of the driver and the elements of the steering system. Therefore, special efforts are made to reduce this phenomenon to a minimum, even at the stage of vehicle design.

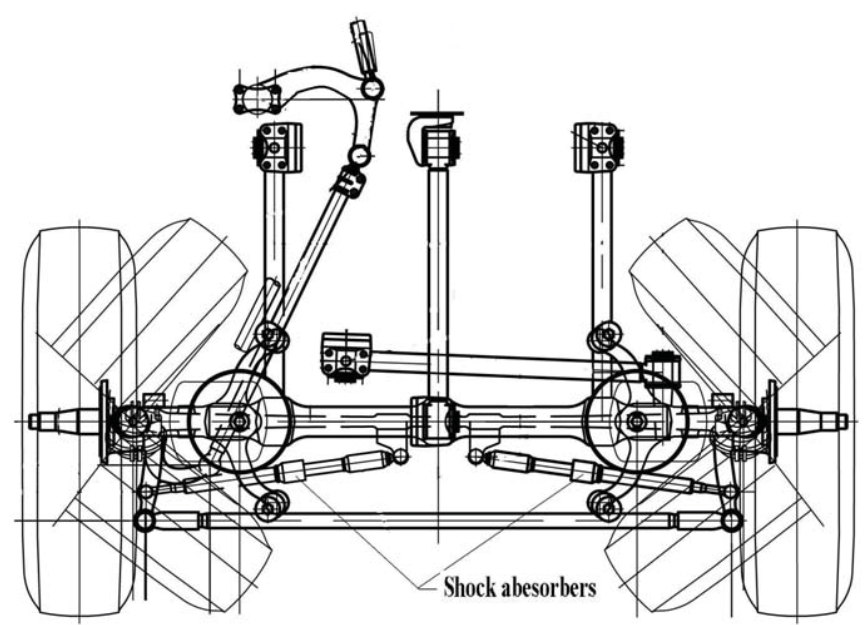

Figure 1: Layout of steering system of a domestic bus with built-in shock absorbers 
For this purpose, sometimes, the design of a steering system incudes shock absorber, schematically shown in Figure 1 [22].

In this paper, the aim was to analyse the validity of this design, through the process of dynamic simulation, which is based on the analysis of a simplified mathematical model of a steering system. Given the complexity of the kinematics and steering system design, as well as the existence of wheels elasticity, deformations of the system, influence of various forces and torques, it is obvious that the modelling of the system represents a significant problem. In the literature [01, 1121] models of different structure and complexity can be found, but bearing in mind that the goal here was to introduce the influence of shock absorbers, built-in in steering trapeze, it was found appropriate to use the model from $[01,17]$ as a basic point. Of course, it has been upgraded by introducing shock absorbers into a steering trapeze, as it will be discussed below.

\section{VIBRATION MODEL OF THE STEERING SYSTEM}

Model of a steering system should include all relevant parameters, such as the influence of allowance in the system, steering mechanism ratio, dry and viscous friction, inertial forces and torques, gyroscopic moments, as well as all active forces and torques acting on the wheels, etc. [17]. Certainly, it is a complex problem that in practice, in the initial stage of design of a steering system, is solved with simplifications so that the model can provide the analysis of the relevant variable, which is in this case damping of shock absorbers in the steering system [03]. Therefore, as a basis for the model, a model with two masses (two angular degrees of freedom) is used, taken from $[01,17]$. As the original model did not include the influence of shock absorbers in the steering trapeze on the steered wheels shimmy, it was necessary to upgrade the model, according to the structural scheme of the steering system shown in Figure 2.

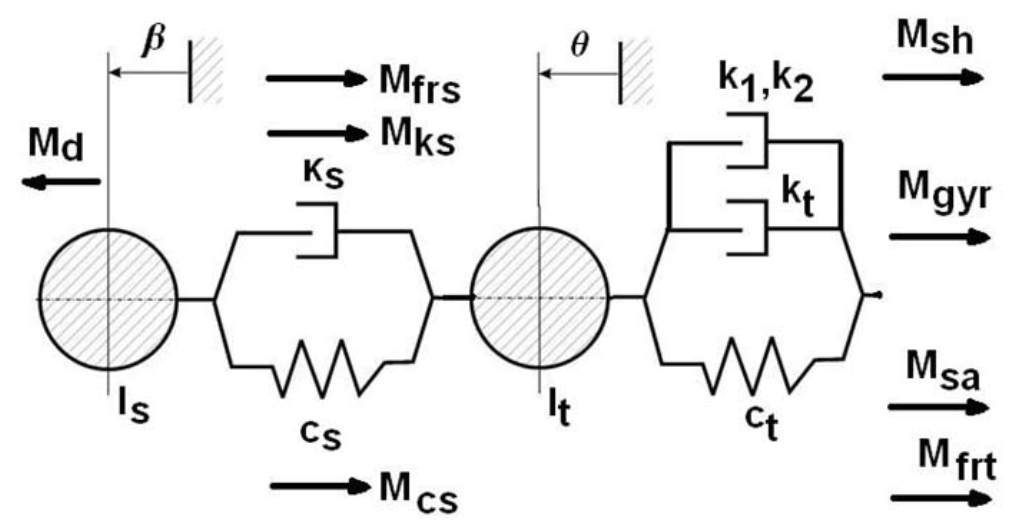

Figure 2: Structural scheme of the applied model of steering system

It is a model of two equivalent masses (power steering and steered wheels) and two degrees of freedom (the angle of the steering wheel refers to the equivalent mass of the power steering, hereinafter referred to as steering angle, and shimmy of the equivalent mass of steered wheels, hereinafter referred to as steered wheels shimmy).

The following symbols were used in Figure 2:

- $\mathrm{M}_{\mathrm{d}}$ - moment on the steering wheel applied by the driver,

- $\mathrm{M}_{\mathrm{frs}}$ - moment of friction in the power steering,

- $\mathrm{M}_{\mathrm{ks}}$ - damping moment of the power steering,

- $M_{c s}-$ moment due to elasticity of the power steering,
- $\mathrm{M}_{\mathrm{sh}}$ - moment due to the built-in shock absorber in the steering trapeze,

- $\mathrm{M}_{\text {gyr }}$ - gyroscopic moment of wheels,

- $\mathrm{M}_{\mathrm{sa}}$-aligning torque of the wheels,

- $M_{\text {frt }}$ - friction torque of the system of steered wheels,

- $\mathrm{I}_{\mathrm{s}}$ - moment of inertia of the equivalent masses of the elements of power steering, and

- $\mathrm{I}_{\mathrm{t}}$ - moment of inertia of steered wheels and related elements of the steering system.

On the basis of $[01,03,11-21]$, the expressions for moments can be written in the following form: 


$$
\begin{aligned}
& M_{d}=M_{\max } \sin (\pi f) \\
& M_{f r s}=c_{f r s} \beta \operatorname{sign}(\beta) \\
& M_{k s}=c_{s}(\beta-\theta) \\
& M_{c s}=c_{s}(\beta-\theta) \\
& M_{g y r}=I_{t} \omega_{t}=I_{t} \frac{v}{r_{d}} \\
& M_{s h}=k_{1} \dot{\theta}+k_{2} \dot{\theta}^{2} \operatorname{sign}(\theta) \\
& M_{f r t}=c_{f r t} \beta \operatorname{sign}(\theta) \\
& M_{s a}=Z_{f}\left(k_{\theta}+c_{\gamma} \gamma+c_{\kappa} \kappa\right)
\end{aligned}
$$

where:

- $M_{\max }-$ maximal torque applied by the driver on the steering wheel,

- $f$-frequency of turning the steering wheel,

- $c_{f r s}, c_{f r t}$ - friction coefficients in power steering and wheels, respectively,

- $v$ - vehicle speed,

- $\omega_{t}$ - angular speed of wheels,

- $r_{d}$-dynamic radius of wheels,

- $Z_{f}$ - vertical reaction on the front axle,

- $k_{\theta}$ - tire sideslip coefficient,

- $c r$-slip coefficient due to caster angle,

- $c_{x}$ - slip coefficient due to wheel convergence,

- $r$ - caster angle, and

- $X$ - convergence angle of steered wheels

Based on Newton's laws and Figure 2, after sorting, differential equations describing the vibration of the observed equivalent masses of the steering system are:

$\ddot{\beta}=\frac{M_{d}-k_{s}(\beta-\dot{\theta})-c_{s}(\beta-\theta)-M_{f r s}}{I_{s}}$

$\ddot{\theta}=\frac{k_{s} \beta+c_{s} \beta-\left(c_{s}+c_{t}\right) \theta-\left(k_{s}+t_{t}\right) \dot{\theta}-M_{s a}-M_{f t t}-M_{g y r}-M_{s h}}{I_{t}}$

The analysis of differential equations (2) and (3) shows that they are with constant coefficients and nonlinear, and need to be solved numerically, as will be discussed later.

\section{DYNAMIC SIMULATION}

Using the model of the steering system described by equations (1) - (3), it is possible to analyse parameters of the built-in shock absorber in steering trapeze, the influence of radial load and the speed of the bus on the steering angle and steered wheels shimmy. In doing so, the analysis is performed for two typical speeds of the bus, 10 and $30 \mathrm{~m} / \mathrm{s}$ and two front axle loads, 50 and $70 \mathrm{kN}$. While driving, the driver acted at the steering wheel with a maximum torque of 2 $\mathrm{N}$, and the variation of the torque on the steering wheel was sinusoidal, with frequency of $1 \mathrm{~Hz}$, because around that value there are commonly found frequencies of drivers action to the steering wheel) [17, 19].
Bearing in mind that the applied model of the steering system was nonlinear, differential equations that describe its vibration motion are solved numerically, by use of Runge - Kutta method. In doing so, the numerical stability is achieved with the time increment of $10-5 \mathrm{sec}$, and the integration is carried out in 262144 points, which ensured the reliability of the results in the domain of 0.38 to $50000 \mathrm{~Hz}$ (which is very high for this type of problem and the results are observed in the area of up to $50 \mathrm{~Hz}$ ).

Dynamic simulation is performed for the tourist bus with the parameters given in Table 1 [22].

Preliminary analyses have shown that in order to follow the further text it is useful to present an illustrative example of a time series steered wheels shimmy, as it is done in Figure 3. From Figure 3 it is evident that shock absorber affects the steering wheels shimmy, and was deemed appropriate to perform the further analyses on the basis of amplitude spectra, calculated by using the software ANALSIGDEM [10]. 
Table 1: Data on the vehicle and its systems

\begin{tabular}{|c|c|}
\hline $\begin{array}{l}\text { Shock absorbers damping coefficient with } \\
\text { the linear member, } k_{1}, \mathrm{Ns} / \mathrm{m}\end{array}$ & 0 (without shock absorbers) 300000 (with shock absorbers) \\
\hline $\begin{array}{l}\text { Shock absorbers damping coefficient with } \\
\text { the square member, } k_{2}, \mathrm{Ns}^{2} / \mathrm{m}^{2}\end{array}$ & 0 (without shock absorbers) 200000 (with shock absorbers) \\
\hline Tire dynamic radius, $r_{d}, \mathrm{~m}$ & 0.556 \\
\hline Steering gear ratio, $i_{u}$, - & 4 \\
\hline $\begin{array}{l}\text { Moment of inertia of the power steering } \\
\text { equivalent mass }, I_{v}, \mathrm{kgm}^{2}\end{array}$ & 15 \\
\hline $\begin{array}{l}\text { Moment of inertia of the steering wheels } \\
\text { equivalent mass, } I_{t}, \mathrm{kgm}^{2}\end{array}$ & 150 \\
\hline $\begin{array}{l}\text { Steered wheels angle of convergence, } \\
X, \mathrm{rad}\end{array}$ & $1 / 360$ \\
\hline Steered wheels caster angle, $\gamma$, rad & $1 / 60$ \\
\hline $\begin{array}{l}\text { Coefficient of tire sideslip } \\
\text { proportionality, } c_{\theta},-\end{array}$ & 20 \\
\hline $\begin{array}{l}\text { Coefficient of sideslip proportionality due to } \\
\text { caster angle, } c r,-\end{array}$ & 0.005 \\
\hline $\begin{array}{l}\text { Coefficient of slip proportionality due to } \\
\text { steered wheels convergence, } c_{\chi^{\prime}}-\end{array}$ & 0.05 \\
\hline Friction coefficients of power steering, $c_{s},-$ & 500 \\
\hline $\begin{array}{l}\text { Power steering damping coefficient, } k_{s} \text {, } \\
1 / \mathrm{rad}\end{array}$ & 50000 \\
\hline Wheels stiffness coefficient, $c_{t}, \mathrm{~N} / \mathrm{rad}$ & 1000 \\
\hline Wheels damping coefficient, $k_{t}, 1 / \mathrm{rad}$ & 10 \\
\hline $\begin{array}{l}\text { Friction coefficient of the wheels system, } \\
k_{t r s},-\end{array}$ & 100 \\
\hline
\end{tabular}

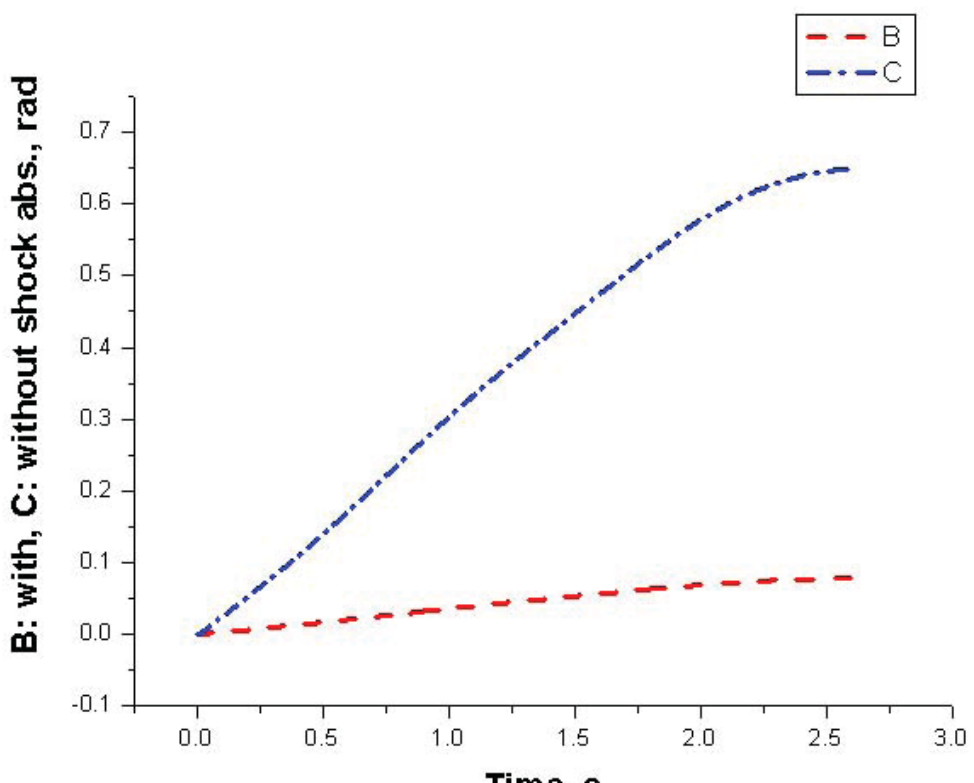

Time, $\mathbf{s}$

Figure 3: Illustration of the impact of shock absorbers on steered wheels shimmy for the speed $30 \mathrm{~m} / \mathrm{s}$ and load 50 daN 


\section{ANALYSIS AND DISCUSSION OF THE RESULTS}

Dynamic simulation enables the analysis of the impact of damping of built-in shock absorbers, radial load and vehicle speed on the steering wheel vibration and steered wheels shimmy.

By using the software [10], mean and RMS values of the time-series are calculated, as the results of dynamic simulation, and the values are given in Table 2.

Table 2: Mean and RMS values of steering angles and steering wheels shimmy

\begin{tabular}{|c|c|c|c||c|c|}
\hline Speed $\mathrm{m} / \mathrm{s}$ & $\begin{array}{c}\text { Front axle } \\
\text { load, N }\end{array}$ & $\begin{array}{c}\text { Mean value of } \\
\text { steering angle, rad }\end{array}$ & $\begin{array}{c}\text { Mean value of } \\
\text { steered wheels } \\
\text { shimmy, rad }\end{array}$ & $\begin{array}{c}\text { Effective value } \\
\text { of steering } \\
\text { angle, rad }\end{array}$ & $\begin{array}{c}\text { Effective value of } \\
\text { steered wheels } \\
\text { shimmy, rad }\end{array}$ \\
\hline 10 & 50000 & $1.58703 \mathrm{E}-003^{*}$ & $7.657674 \mathrm{E}-002^{*}$ & $1.92179 \mathrm{E}-003^{*}$ & $9.12244 \mathrm{E}-002^{*}$ \\
\hline 10 & 50000 & $1.58703 \mathrm{E}-003^{* *}$ & $1.009701 \mathrm{E}-002^{* *}$ & $1.92179 \mathrm{E}-003^{* *}$ & $1.19799 \mathrm{E}-002^{* *}$ \\
\hline 10 & 70000 & $1.58703 \mathrm{E}-003^{*}$ & $8.381248 \mathrm{E}-002^{*}$ & $1.92179 \mathrm{E}-003^{*}$ & $1.00708 \mathrm{E}-001^{*}$ \\
\hline 10 & 70000 & $1.58703 \mathrm{E}-003^{* *}$ & $1.095510 \mathrm{E}-002^{* *}$ & $1.92179 \mathrm{E}-003^{* *}$ & $1.30989 \mathrm{E}-002^{* *}$ \\
\hline 30 & 50000 & $-1.157885 \mathrm{E}-003^{*}$ & $3.736105 \mathrm{E}-001^{*}$ & $4.39064 \mathrm{E}-003^{*}$ & $4.26686 \mathrm{E}-001^{*}$ \\
\hline 30 & 50000 & $-1.15788 \mathrm{E}-003^{* *}$ & $4.466578 \mathrm{E}-002^{* *}$ & $4.39064 \mathrm{E}-003^{* *}$ & $5.10057 \mathrm{E}-002^{* *}$ \\
\hline 30 & 70000 & $-1.15788 \mathrm{E}-000^{*}$ & $-7.37474 \mathrm{E}+000^{*}$ & $4.39064 \mathrm{E}-000^{*}$ & $1.19403 \mathrm{E}+000^{*}$ \\
\hline 30 & 70000 & $-1.15788 \mathrm{E}-003^{* *}$ & $4.540509 \mathrm{E}-002^{* *}$ & $4.39064 \mathrm{E}-003^{* *}$ & $5.16531 \mathrm{E}-002^{* *}$ \\
\hline \hline
\end{tabular}

* Without shock absorbers ** With shock absorbers

It was estimated to be expedient, in addition to statistical values given in Table 2, using the same software, to calculate amplitude spectra of the observed variables. For illustration, the amplitude spectra of the steering wheel angle are partially shown in Figures 4 and 5.

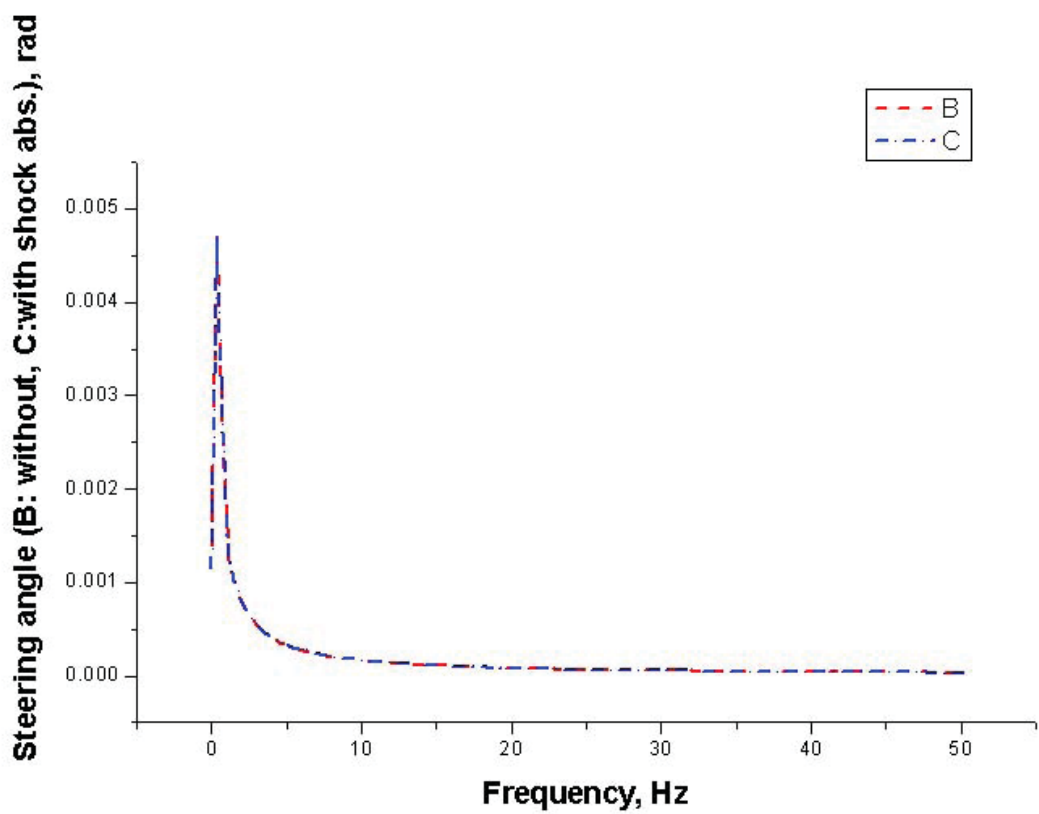

Figure 4: Steering angle for a speed of $30 \mathrm{~m} / \mathrm{s}$ and $70 \mathrm{kN}$ radial load of front axle

Analysis of all the data, partially shown in Figures 4 and 5 showed that the greatest power of amplitude spectra of the steering angle is distributed within the area until about $2 \mathrm{~Hz}$, which is consistent with [17]. In addition, it can be seen that the installation of shock absorbers insignificantly affects the steering angle, for both vehicle speeds, which also refers to the influence of the load of steered wheels on the aforementioned parameter. The obvious match of graphs relating the status - with or without shock absorbers is a result of significant damping effect of power steering itself and partly a result of simplifications introduced in the vehicle model. 


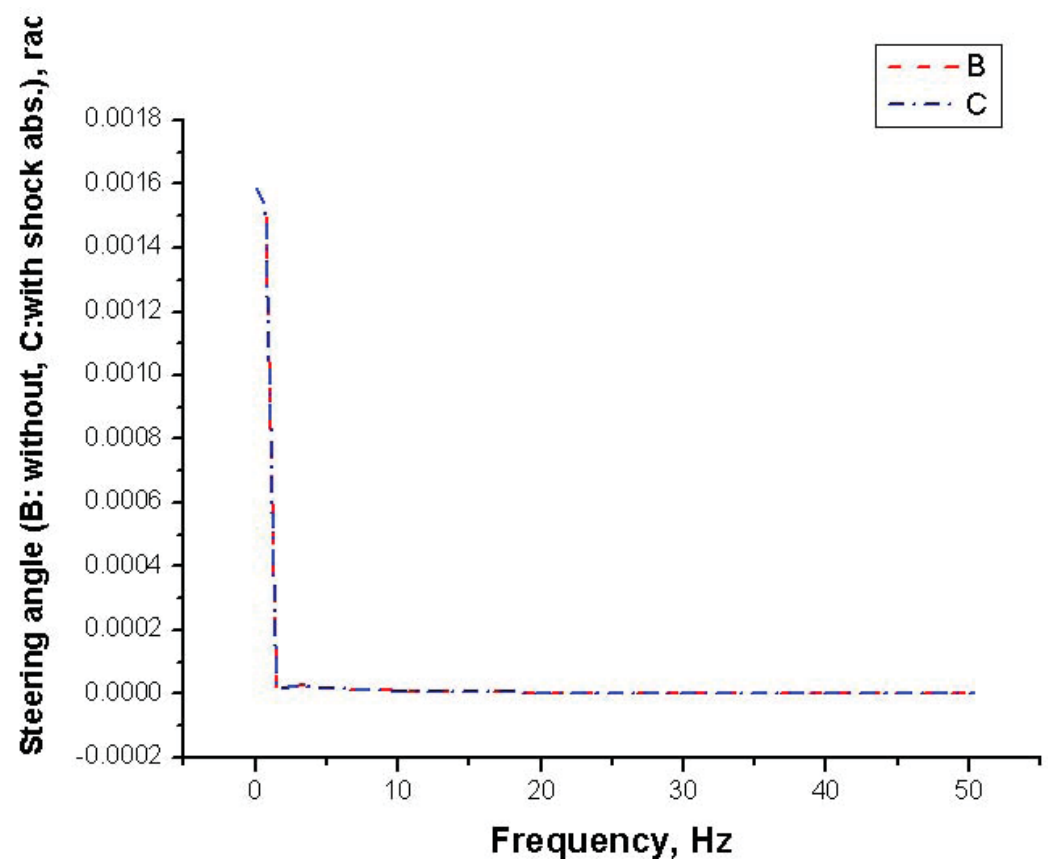

Figure 5: Steering angle for a speed of $10 \mathrm{~m} / \mathrm{s}$ and $70 \mathrm{kN}$ radial load of front axle

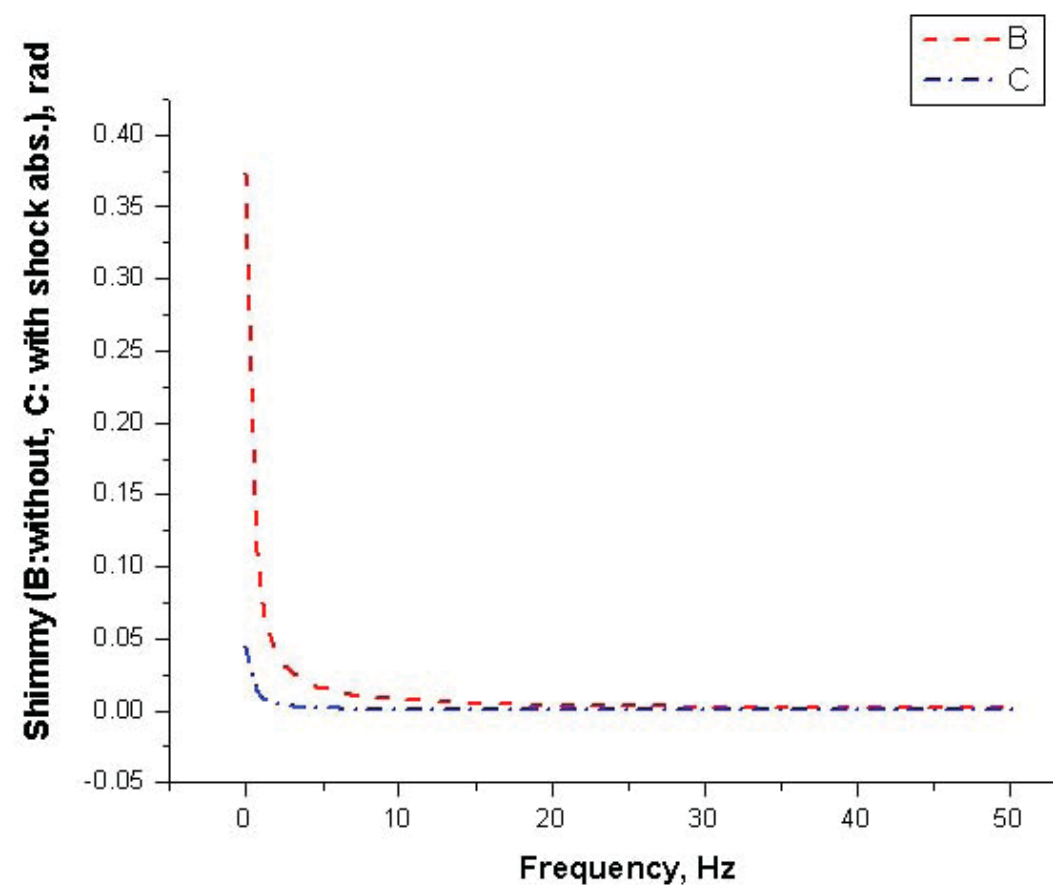

Figure 6: Steered wheels shimmy for speed $30 \mathrm{~m} / \mathrm{s}$ and $50 \mathrm{kN}$ radial load of front axle

However, the speed of the vehicle influences the steering since the increase of speed leads to the increase of amplitude spectra of the observed parameter (this fact can be explained as the influence of gyroscopic moment which exists in differential equations of motion of the observed vibration model of the steering system).

Dynamic simulation enabled the analysis of the impact of damping of built-in shock absorbers, radial load and vehicle speed on the steered wheels shimmy. For illustration purposes, the results of dynamic simulation are partly shown in Figures 6 and 7 .

The analysis of the data, partly shown in Figures 6 and 7 , can confirm that the installed shock absorbers significantly decrease steered wheels shimmy, especially in the area up to $15 \mathrm{~Hz}$, which is very important for vehicle ride comfort [21]. 


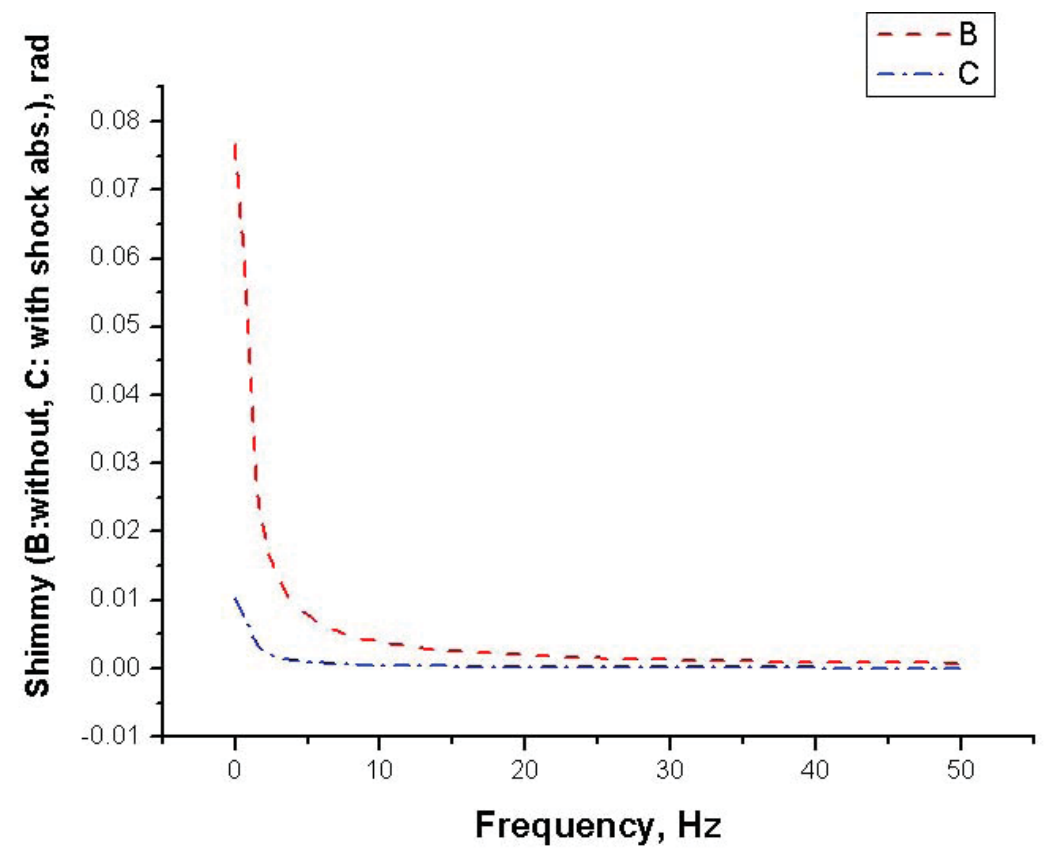

Figure 7: Steered wheels shimmy for speed $10 \mathrm{~m} / \mathrm{s}$ and $50 \mathrm{kN}$ radial load of front axle

This certainly justifies the installation and application of shock absorbers in the steering system trapeze, even though it complicates the design and increases the vehicle cost.

In this case, the value of shimmy increases with the increase of the load of steered wheels, which is easily explained by the fact that the parameters of the tire lateral stiffness which exist in the applied model of the steering system increase with the growth of radial load of the tire. Bus speed also shows the impact on the steered wheels shimmy. In fact, the increase of speed leads to the increase of steered wheels shimmy, which can be related to the increase of the value of gyroscopic moments that are included in the model of the bus steering system.

\section{CONCLUSIONS}

Based on the performed study the following can be concluded:

- The applied simplified vibration model of a bus steering system can be used at the initial stages of vehicle design to enable the analysis of the dynamic phenomena in the mentioned system.

- Practical design solutions of the steering system trapeze with the built-in shock absorbers have their own justification, as a shock absorber significantly reduces steered wheels shimmy at lower frequencies, in re- gimes of variable vehicle speed and radial load of wheels. In doing so, shock absorber doesn't show a higher impact on the steering angle, except in the case of vehicle speed variation.

\section{REFERENCES}

1) Abe, M., Manning, W. (2009) Vehicle Handling Dynamics, Elsevier.

2) Bendat J.S., Piersol A.G. (2000) Random Data Analysis and Measurement Procedures. John Wiley and Sons, London.

3) Demić, M. (1996) Analysis of Influence of Design Parameters on Steered Wheels Shimmy of Heavy Vehicles. Vehicle Syst. Dyn. 26: 343-379

4) Demić, M., Diligenski Đ. (1999) The Optimization of Suspension Geometry Parameters of Bus Steered Wheels, Third International Conference Heavy Mashinery-HM'99, Kraljevo.

5) Demić, M., Diligenski, Đ. (2000) The sensitivity analysis and the optimization of suspension geometry parameters of bus steered wheels, MVM 1,2.

6) Demić, M. (2000) Optimization of the steering wheels geopmetry of motor vehicles (in Serbian), Tehnika br. 3.

7) Demić, M. (2002) Some aspects of the investigation of the shimmy of the steered truck's wheels (in Serbian), Vojnotehnički glasnik 3 
8) Demić, M. Diligenski, Đ. (2013) A contribution to research of the influence of degradation of vehicle vibration parameters on thermal load of shock absorbers, Journal of Applied Engineering Science, Vol.11, No. 1, pp 23-30.

9) Demić, M., Diligenski, Đ. (2012) A Contribution to Research of Degradation of Characteristics of Vibration Parameters on Vibration Aspect of Vehicle Comfort, Journal of Applied Engineering Science, Vol. 10, No. 4, pp.185190.

10) Demić, M. Software "Analsigdem", www.ptt. $\mathrm{yu} / \mathrm{korisnici} / \mathrm{i} / \mathrm{m} / \mathrm{imizm} 034$.

11) Ellis, J.R. (1994) Vehicle Handling Dynamics. Mechanical Engineering Publications Limited, London.

12) Fiala, E. (2006) Mensch und Fahrzeug. ATZ/ MTZ, Springer Verlag.

13) Gincburg, L. L. (1997) Driver model for investigation of vehicle motion at desired trajectory. Avtomobilnaja promisljenost, No. 8: 11-16 (in Russian).
14) Gillespie, T. (1992) Fundamentals of Vehicle Dynamics. SAE, Warrendale

15) Genta, A. (2003) Motor Vehicle Dynamics. Politecnika di Torino.

16) Georg, R. (2004) Vehicle Dynamics. Lecture Notes, Fachhochschule Regensburg.

17) Hačaturov, A.A. et al. (1976) Dynamics of System: Road-Tire-Vehicle-Driver. Mašinostrojenije, Moscow (in Russian).

18) Miliken, W.F., Miliken, D.L. (1995) Race Car Vehicle Dynamics. SAE, Warrendale.

19) Mitschke, M. (1972) Dynamik der Kraftfahrzeuge. Springer Verlag .

20) Rajamani, R. (2006) Vehicle Dynamics and Control. Springer Verlag.

21) Simić, D. (1988) Motor Vehicle Dynamics. Naučna knjiga, Belgrade (in Serbian),

22) FAP (2013) Information (in Serbian).

Paper sent to revision: 01.07.2013.

Paper ready for publication: 04.09.2013. 